\title{
INDICADORES DE OFERTA DA EDUCAÇÃO À DISTÂNCIA NA REDE FEDERAL DE EDUCAÇÃO PROFISSIONAL, CIENTÍFICA E TECNOLÓGICA APÓS 10 ANOS DE INSTITUCIONALIZAÇÃO
}

\author{
Cleberton Carvalho Soares ${ }^{1}$ \\ Danielle Amaral Menendez ${ }^{2}$ \\ Andrés Ignácio Martinez Menendez ${ }^{3}$ \\ DOI: $10.29327 / 3860.13 .23-5$
}

\section{Resumo}

A partir promulgação da Lei de Diretrizes e Bases da Educação no ano de 1996, a educação à distância ganhou notoriedade no Brasil e foi destacada como uma modalidade estratégica para levar a oportunidade de escolarização para todo o país. Dois anos após foram criados os Institutos Federais de Educação, Ciência e Tecnologia, pertencentes a Rede Federal de Educação. O objetivo deste artigo é aferir através dos indicadores da base de alunos nos Institutos Federais como está a oferta de cursos de nível superior na modalidade a distância, considerando a análise dos dados referente a 2019, ano em que alcançam uma década de sua criação. Os resultados apontam que o uso da educação a distância possibilita o alcance maior da sociedade e que a oferta ocorre para todos os tipos de cursos superiores, mas ainda não está disseminada em todos os estados brasileiros onde possui unidades de ensino da referida instituição escolar.

Palavras chaves: Instituto Federal; Educação a Distância; Educação Pública.

\section{OFFER INDICATORS OF DISTANCE EDUCATION IN THE FEDERAL}

\section{NETWORK OF PROFESSIONAL, SCIENTIFIC AND TECHNOLOGICAL} EDUCATION AFTER 10 YEARS OF INSTITUTIONALIZATION

\begin{abstract}
Since the enactment of the Law of Directives and Bases of Education in 1996, distance education gained notoriety in Brazil and was highlighted as a strategic modality to take the opportunity of schooling to the whole country. Two years later, the Federal Institutes of Education, Science and Technology were created, belonging to the Federal Education Network. The purpose of this article is to assess through the indicators of the student base at Federal Institutes how is the offer of higher education courses in the distance modality, considering the data analysis referring to 2019 , the year in which they reach a decade of its creation. The results show that the use of distance education makes it possible for society to
\end{abstract}

\footnotetext{
${ }^{1}$ Mestre em Sistema e Computação Instituto Federal de Sergipe

${ }^{2}$ Mestre em Sistema e Computação Instituto Federal de Sergipe

${ }^{3}$ Mestre em Informática Universidade Federal de Sergipe
} 


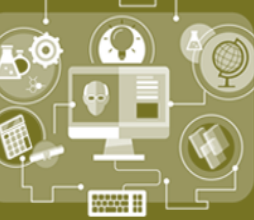

reach more and that the offer occurs for all types of higher education, but it is not yet widespread in all Brazilian states where it has teaching units from the said school institution.

Keywords: Federal Institute. Distance Education. Public Education.

\section{Introdução}

A Lei No 9.394, de 20 de dezembro de 1996 - Lei de Diretrizes e Bases da Educação (LDB), mais especificamente em seu Art. $80^{\circ}$ define que "O Poder Público incentivará o desenvolvimento e a veiculação de programas de ensino a distância, em todos os níveis e modalidades de ensino, e de educação continuada". Em legislação atual que regulamenta o referido artigo, o Decreto $N^{\circ}$ 9.057, de 25 de maio de 2017, define em seu Artigo $2^{\circ}$ que "a educação básica e a educação superior poderão ser ofertadas na modalidade a distância nos termos deste Decreto, observadas as condições de acessibilidade que devem ser asseguradas nos espaços e meios utilizados" (grifo nosso).

Cerca de doze anos da promulgação da LDB, as instituições de ensino centenárias, conhecidas popularmente como "escolas técnicas", passaram a compor a Rede Federal de Educação Profissional, Científica e Tecnológica, denominando-se como Institutos Federais de Educação, Científica e Tecnologia (IF) na condição de autarquias federais. $\mathrm{O}$ ato legal foi promulgado através da Lei $\mathrm{N}^{\circ} 11.892$, de 29 de dezembro de 2008, a qual passou-se a ser conhecida como a "Lei dos Institutos". Dentre outras definições, de acordo com o Art. $2^{\circ}$ da Lei dos Institutos, a estruturação dos IF é multicampi por cada ente da federação, sendo cada Campus do IF denominado de Unidade de Ensino (UE). Assim, cada estado tem vários campi. No âmbito da sua autonomia, conforme parágrafo $3^{\circ}$ é previsto que os IF podem “criar e extinguir cursos, no limite de sua atuação territorial”, mediante deliberação do órgão Conselho Superior.

Aos pertencentes desta rede federal, foi confiada a missão de atuar em todos os níveis de ensino, desde a educação básica à pós-graduação stricto sensu. Destaca-se que, para o nível de graduação, os IF têm equiparação as universidades federais. Com base na regulação atual 


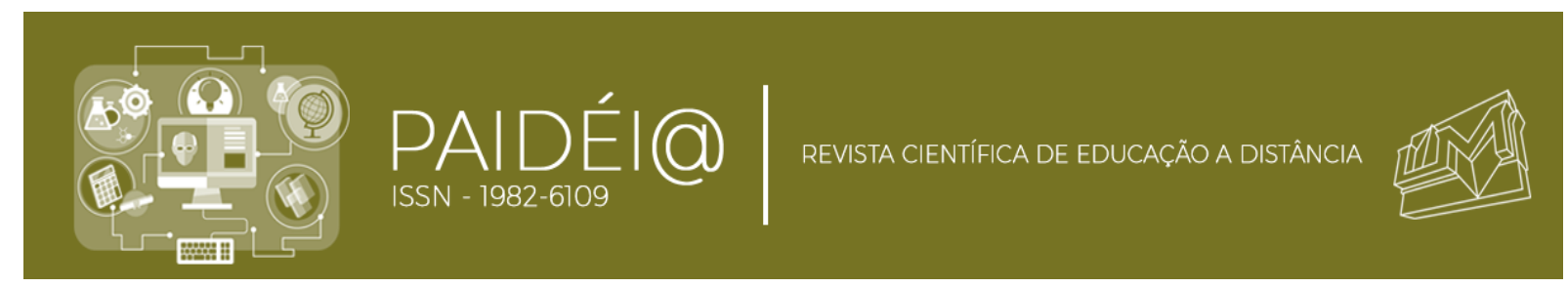

da legislação da educação superior em vigor, as universidades gozam da autonomia na oferta de seus cursos à comunidade, quer seja presencial ou à distância, onde são dispensados os atos regulatórios definidos como autorização de cursos superiores (SINAES, 2004). Assim, considerando que a lei de criação dos IF ocorreu no final de 2008, havia condições de ofertar cursos superiores à comunidade a partir do ano de 2009; ou seja, em 2019 completara 10 anos como uma instituição de ensino superior (IES).

Conforme apresentam FAVERI et al (2018), durante o período de 2004 a 2016 houve uma política de expansão dos IF, com destaque às cidades interioranas em todas as regiões brasileiras. Consequentemente, a fim de atender a referida ampliação, concursos públicos para ingresso nos IF tiveram que ser ampliados, com oportunidades tanto para profissionais de nível médio e superior para técnicos administrativos quanto para o exercício da docência como professor da educação básica, técnica e tecnológica (EBTT) em regime de dedicação parcial, integral ou integral com dedicação exclusiva - esta última, impede ao docente firmar outros vínculos empregatícios, exceto os previstos na Lei $\mathrm{N}^{\circ} 12.772$, de 28 de dezembro de 2012.

No tocante as questões tecnológicas, Moran (2011, p. 41) comenta que existe um "conjunto de ações de ensino-aprendizagem são desenvolvidas por meio de meios telemáticos, como a Internet, a videoconferência e a teleconferência”. Uma vez que aquisições de produtos e serviços no âmbito governamental exigem um processo licitatório quando requer o pagamento de valores, uma alternativa quando ao uso de ambiente virtual de aprendizagem (AVA) é o Modular Object-Oriented Dynamic Learning Environment (MOODLE). O MOODLE, conforme apresenta Sebastião (2015), é um software para gestão de curso, gratuito, com código aberto, baseado na Web, que oferece diversos recursos de apoio ao ensino e a aprendizagem a distância, sendo um dos mais utilizados no Brasil (CARLINI, TARCIA, 2010); assim, pode ser utilizado livremente pelas instituições de ensino, particularmente os IF como AVA da oferta de cursos superiores a distância.

As instituições de ensino devem estar atualizadas para acompanhar intensivamente as mudanças que ocorreram e continuam ocorrendo na sociedade (MUSSIO, 2020). O principal pilar de qualquer instituição de educação é o ensino, independentemente da modalidade, permitindo à comunidade acadêmica sempre melhores condições em iniciar, manter e 
desenvolver sua aprendizagem. Este trabalho tem por objetivo analisar a oferta, através da modalidade à distância, de cursos de nível superior (Licenciatura, Bacharelado e Tecnologia) no Brasil através dos IF em 2019, ano em que alcança 10 anos como uma IES gozando de autonomia universitária.

\section{Metodologia}

Esse estudo tem a natureza exploratória. Para Oliveira (2011 apud Zikmund, 2000), os estudos exploratórios, geralmente, são úteis para diagnosticar situações, explorar alternativas ou descobrir novas ideias. O objetivo desse tipo de estudo é procurar padrões, ideias ou hipóteses. A ideia não é testar ou confirmar uma determinada hipótese, mas realizar descobertas. Dessa forma, mesmo quando já existem conhecimentos do pesquisador sobre o assunto, a pesquisa exploratória também é útil, uma vez que, para um mesmo fato organizacional, pode haver inúmeras explicações alternativas e sua utilização permitirá ao pesquisador tomar conhecimento, senão de todas, pelo menos de algumas delas.

Com o intuito de averiguar os indicadores quanto a oferta da Educação a Distância (EaD) pelos IF, será utilizado como variáveis de análise a base de alunos, o quantitativo cursos e matrículas dos IF, classificados pelas regiões brasileiras, observando os percentuais de representatividade dos percentuais das ofertas da $\mathrm{EaD}$ em relação ao total que cada estado tem de matrículas. Os dados a serem utilizados foram extraídos da Plataforma Nilo Peçanha 2020 (PNP 2020), cujos resultados foram publicados originalmente em maio de 2020 e atualizados no mês seguinte (PNP 2020).

A PNP 2020, conforme estabelece a Portaria MEC Nº 1, de 3 de janeiro de 2018 é o ambiente virtual de coleta, validação e disseminação das estatísticas oficiais da Rede Federal de Educação Profissional, Científica e Tecnológica (Rede Federal), onde são dispostas as informações acadêmicas do corpo discente no ano de 2019. Assim, considerando ter sido instituído ao final de 2008, portanto com possibilidade de iniciar a oferta de cursos superiores em 2009, a análise refere-se a base de alunos EaD no ano em que os IF completaram a primeira década de institucionalização como uma IES. 
No intento de preservar o aspecto propositivo e acadêmico do artigo, as análises foram realizadas no âmbito regional, fazendo uso da anonimização quanto aos respectivos IF, exceto para os indicadores que se mostraram positivos e destacados.

As questões a serem respondidas a partir dos dados levantados são:

1. Qual a base de alunos dos IF de cursos superiores vinculados a EaD?

2. Qual a quantidade de cursos e matrículas ofertados?

3. Quais os tipos de cursos ofertados na modalidade a distância?

4. Qual a representatividade do percentual na oferta dos cursos superiores à distância frente ao presencial?

\section{Base de Alunos dos IF em 2019}

Considerando os dados dispostos na Tabela 1, identifica-se que em 2019 havia 482 unidades de ensino do IF no Brasil as quais ofertaram cursos de nível superior para um total de 291.814 discentes. Em termos percentuais, cerca $17 \%$ dessas unidades fizeram a oferta de cursos à distância, totalizando 83, para 25.311 alunos. Assim, para o ano de 2019, apura-se que 9\% da base de alunos dos cursos superiores dos IF era atendida através da a modalidade EaD.

Tabela 1: Oferta de Cursos Superiores no Brasil pelos IF em 2019

\begin{tabular}{|c|c|c|c|c|}
\hline \multirow{2}{*}{ VARIÁ VEL } & \multicolumn{4}{|c|}{ BRASIL } \\
\cline { 2 - 5 } & PRESENCIAL & EAD & TOTAL & \% EaD \\
\hline UNIDADES DE ENSINO & 482 & 83 & 482 & $17 \%$ \\
\hline MATRÍCULAS & 266.503 & 25.311 & 291.814 & $9 \%$ \\
\hline CURSOS SUPERIORES & 2.110 & 127 & 2.237 & $6 \%$ \\
\hline BACHARELADO & 666 & 6 & 672 & $1 \%$ \\
\hline LICENCIATURA & 693 & 106 & 799 & $13 \%$ \\
\hline TECNOLOGIA & 751 & 15 & 766 & $2 \%$ \\
\hline
\end{tabular}

Fonte: Elaborado pelos autores com base na PNP 2020

No Gráfico 1 apresenta-se a distribuição quantitativa da base de alunos de cursos superiores nos IF pelos tipos existentes: Bacharelado, Licenciatura e Tecnologia, com base na PNP 2020. As modalidades estão dispostas nas cores, sendo azul e laranja para a modalidade presencial e a distância, respectivamente. Notadamente os cursos de Licenciatura (799) e de Tecnologia (766), com uma pequena diferença entre eles no total da oferta, representam os 
tipos de cursos superiores com maior predominância de funcionamento. Em 2019, o Bacharelado teve uma oferta de 672 cursos no total.

\section{Gráfico 1 - Oferta de Cursos Superiores no Brasil pelos IF}

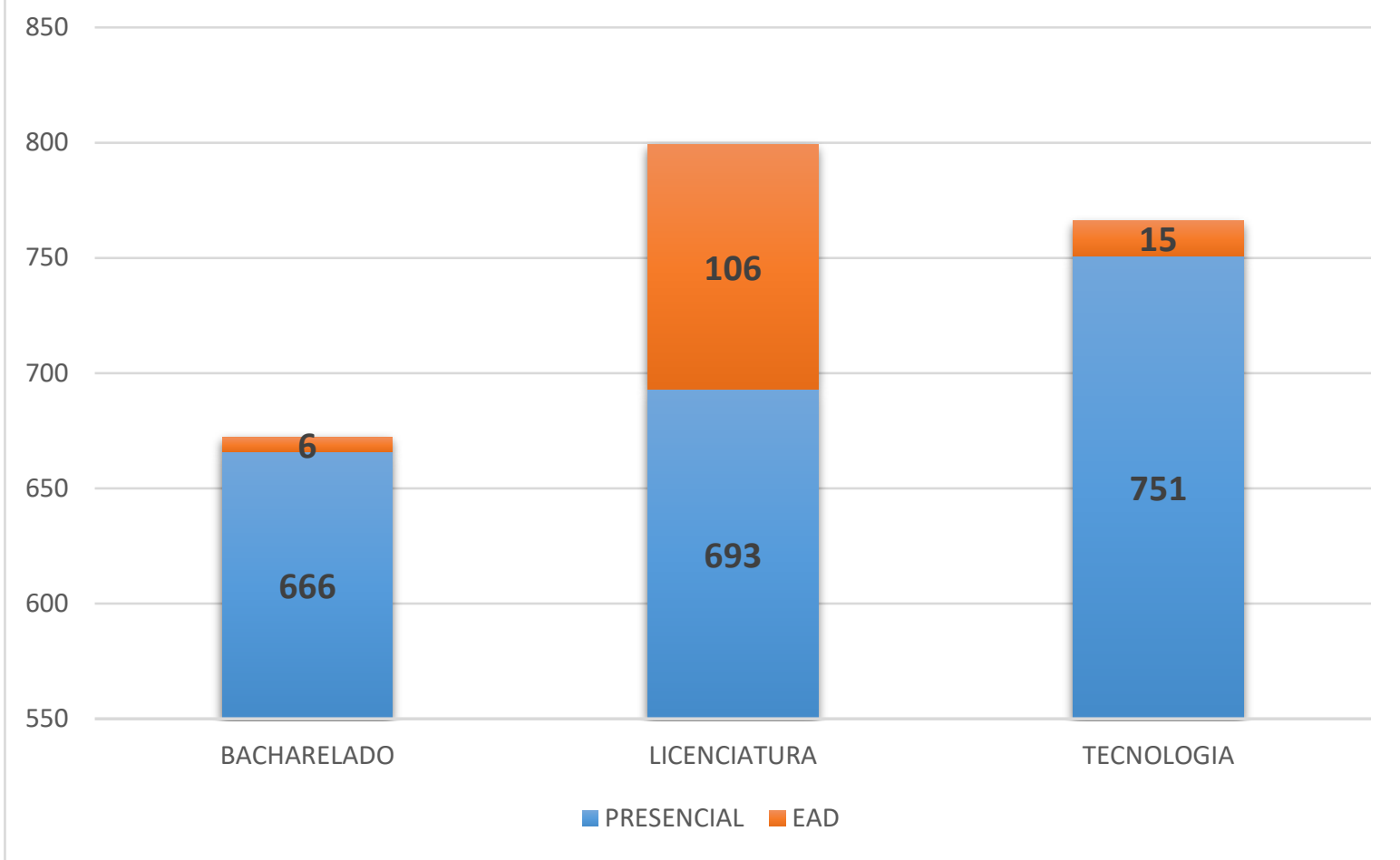

Fonte: Elaborado pelos autores com base na PNP 2020

Considerando a modalidade de ensino, a partir dos dados da PNP 2020, identifica-se que há uma discrepância relevante na oferta no período. No Bacharelado, aproximadamente $1 \%$ é ofertado através da $\mathrm{EaD}$, num total de 6 cursos ofertados, enquanto 666 são ofertados na modalidade presencial. No tocante aos cursos de Tecnologia, apesar do quantitativo maior na oferta se comparado ao Bacharelado (15, no total), em termos percentuais, apura-se que apenas $2 \%$ da oferta deste tipo de curso na modalidade a distância - são 751 cursos ofertados presencialmente. Nas Licenciaturas a oferta é de 106 e 693 cursos na EaD e presencial, respectivamente, o que se permite o alcance de um indicador mais relevante no percentual, chegando a $13 \%$ do total do referido tipo de curso ofertado a comunidade através da educação a distância pelos IF no Brasil.

Na variável de matrículas, no âmbito nacional, os IF têm em torno de 9\% (25.311) da sua base discente vinculada a 127 cursos de graduação ofertados na EaD em 2019, o que permite alcançar uma média de quase 200 discentes/curso, conforme a PNP 2020. Considerando a 
mesma análise para a modalidade presencial (266.503/2.110), essa média é bem inferior, cujo indicador apurado chega a 126 discentes/curso; ou seja, $60 \%$ inferior que os cursos à distância. Assim, observa-se que a implementação da EaD representa uma alavanca para ampliar a abrangência dos IF ante a comunidade na oferta de cursos superiores.

A Tabela 2 mostra a representação quantitativa referente a oferta de cursos superiores nos IF divididos pelas regiões brasileiras. Referente ao quantitativo de unidades de ensino que ofertam cursos superiores a distância, conforme disposto na Tabela 2, nota-se que o Nordeste é a região que apresenta o maior indicador, com 21 unidades de ensino. No entanto, em termos percentuais, apura-se que o Norte dispõe de $1 / 4$ de suas unidades com ofertas de cursos superiores através da $\mathrm{EaD}$, sendo ela a região que detém o primeiro lugar.

Tabela 2 - Oferta de Cursos Superiores pelos IF por Região

\begin{tabular}{|l|c|c|c|c|c|c|c|c|c|}
\hline \multirow{2}{*}{ REGIÃO } & \multicolumn{3}{|c|}{ UNIDADES DE } & \multicolumn{4}{c|}{ CURSOS } & \multicolumn{3}{c|}{ MATRICULAS } \\
\cline { 2 - 12 } & Presencial & EaD & $\%$ & Presencial & EaD & $\%$ & Presencial & EaD & $\%$ \\
\hline Norte & 51 & 13 & 25 & 250 & 22 & 8 & 23.152 & 1.575 & 7 \\
\hline Nordeste & 148 & 31 & 21 & 655 & 50 & 7 & 82.130 & 7.358 & 9 \\
\hline Sul & 92 & 16 & 17 & 381 & 20 & 5 & 45.344 & 2.113 & 4 \\
\hline Sudeste & 128 & 11 & 9 & 575 & 20 & 3 & 84.203 & 9.595 & 11 \\
\hline Centro- & 63 & 12 & 19 & 249 & 15 & 6 & 31.674 & 4.670 & 15 \\
Oeste & & & & & & & & & \\
\hline
\end{tabular}

Fonte: Elaborado pelos autores com base na PNP 2020

Ademais o quantitativo expressivo da região Nordeste, ainda com base na Tabela 2, verificase que há uma proximidade entre as demais regiões, tendo o Sul com 16; o Norte com 13; Centro-Oeste com 12; e o Sudeste ocupa a última posição no referido indicador. No entanto, sob a análise do indicador percentual, o Norte desponta em posição de vanguarda, conforme já discutido no parágrafo anterior, seguindo com menores diferenças do que o indicador quantitativo, onde o Nordeste tem 21\%; o Centro-Oeste com 19\%; e o Sul com 17\%. A região Sudeste dispõe de um indicador com menor expressividade, onde apenas $9 \%$ das suas unidades de ensino ofertam cursos superiores através da EaD. A Figura 1 mostra um ranking por região a partir dos indicadores discutidos; e na Figura 2 um mapa quantitativo do 
panorama nacional onde os IF dispõem de unidade de ensino que oferta cursos superiores a distância.

Figura 1 - Ranking das Regiões Brasileiras com Unidades de Ensino dos IF que Ofertam Cursos Superiores a Distância

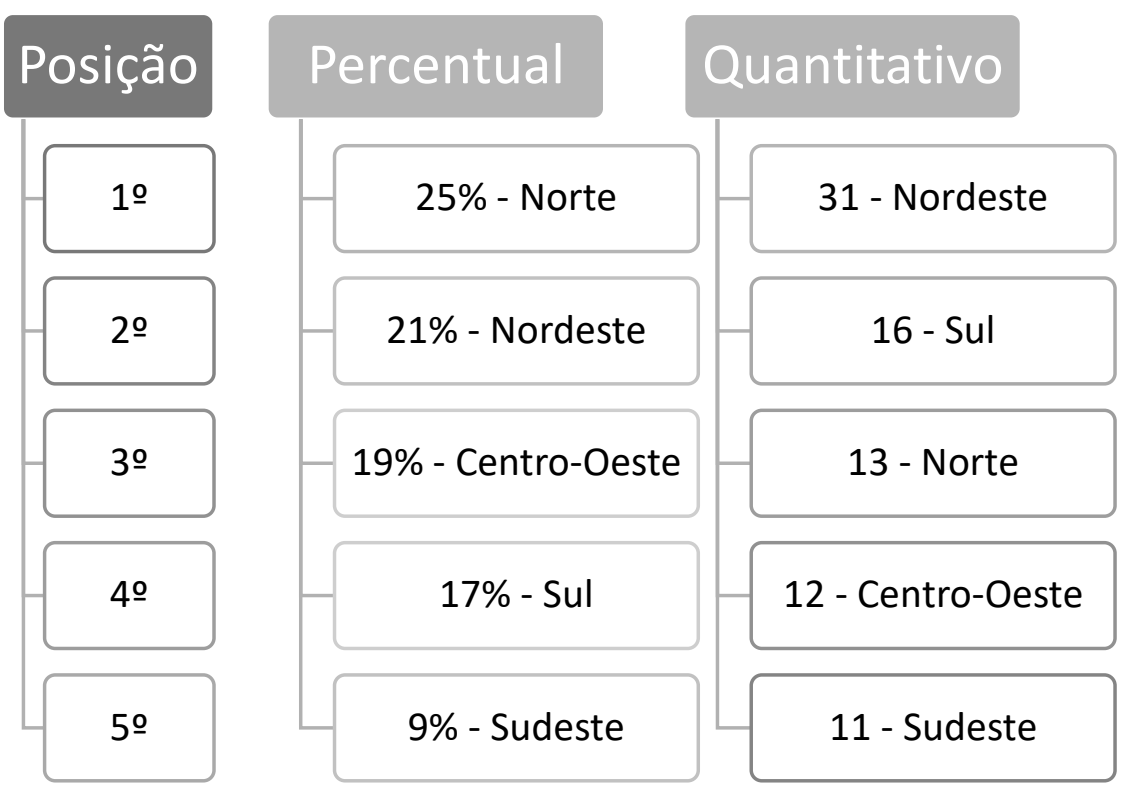

Fonte: Elaborado pelos autores com base na PNP 2020 


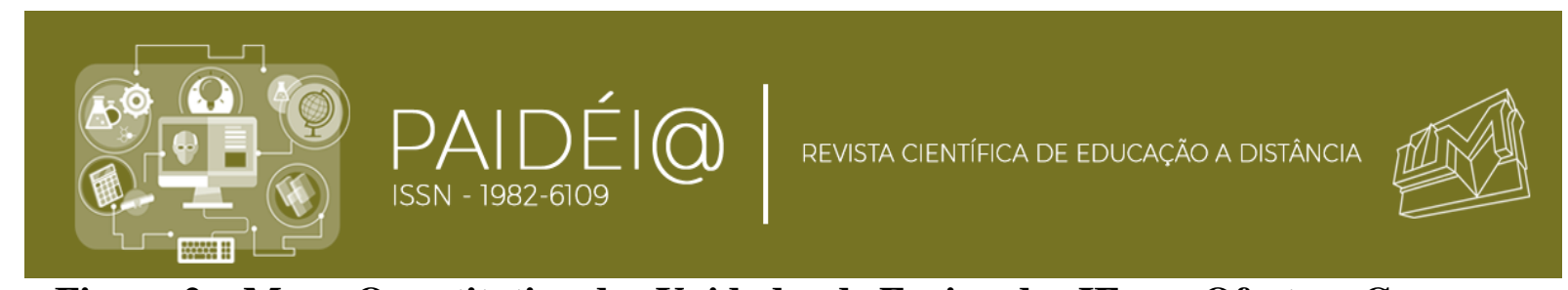

Figura 2 - Mapa Quantitativo das Unidades de Ensino dos IF que Ofertam Cursos Superiores a Distância

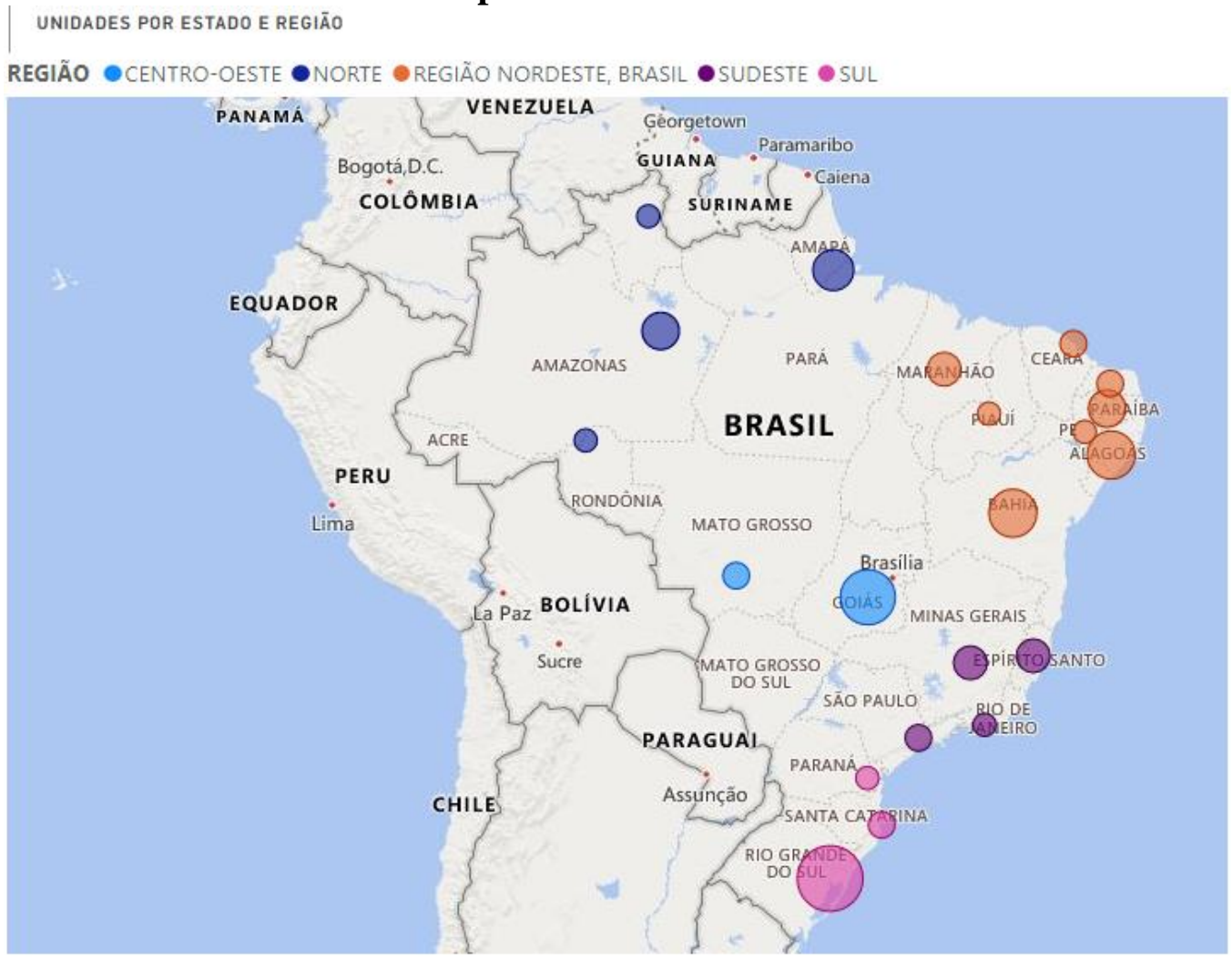

Fonte: Elaborado pelos autores com base na PNP 2020

Na Quadro 1 são relacionados os estados que em 2019 não registraram na PNP 2020 a oferta de cursos superiores através da $\mathrm{EaD}$, a qual mostra que a região com maior número de estados com a referida ausência é o Norte, com 3 estados; seguido pelo Nordeste e CentroOeste, ambos com 1 estado, sendo Sergipe e Mato Grosso do Sul, respectivamente. No Sul e Sudeste há a referida oferta na totalidade dos estados pertencentes a região.

Quadro 1: Total de Estados sem Oferta de Cursos Superiores à Distância

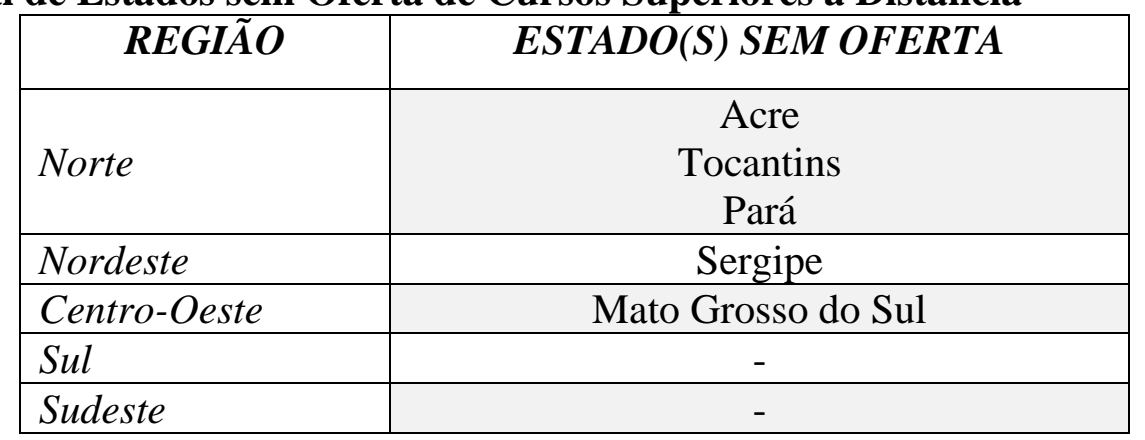

Fonte: Elaborado pelos autores com base na PNP 2020 
Na sequência da discussão dos resultados dispostos na Tabela 2, a próxima variável a ser analisada será referente "Matrículas", a qual dispõe da base de discentes que os IF registraram na PNP 2020 estarem vinculados a cursos superiores ofertados na modalidade EaD.

Considerando o quantitativo de matrículas, a região Sudeste ocupa a liderança destacada neste indicador que supera os 2.000 alunos em relação ao segundo colocado, com um total de 9.595 matrículas registradas, apesar do menor número de unidades de ensino que dispõem da oferta de cursos superiores a distância. Como a segunda região com melhor indicador em cursos superiores à distância está o Nordeste, com 7.358 matrículas, também com larga diferença para o terceiro - Centro-Oeste com 4.670 discentes matriculados. O Sul e o Norte registraram 2.113 e 1575 matrículas, respectivamente.

A partir da análise do percentual da base de alunos expressos na Tabela 2, o Centro-Oeste apresenta o melhor indicador dentre as regiões, com 15\%. O segundo lugar (11\%) é da região Sudeste, seguido pelo Nordeste (9\%), Norte (7\%) e o Sul (4\%). Nota-se que a diferença entre o Sudeste, Nordeste e Norte é constante em dois pontos percentuais.

A partir dos percentuais e quantitativos apurados, o ranqueamento por regiões e um panorama por estado brasileiro das matrículas registadas em 2019 na PNP 2020 em cursos superiores através da $\mathrm{EaD}$, ofertados pelos IF, estão dispostos na Figura 3 e Figura 4, respectivamente. A partir da análise dos ranqueamentos, observa-se que a região Nordeste tem uma ligeira variação entre o segundo (percentual) e terceiro (quantitativo) lugares entre os valores percentuais e quantitativos. As regiões Sul e Norte mantém-se em quarta e quinta posições, respectivamente em todos ambos os aspectos. 


\section{PAIDÉl@ \\ ISSN - 1982-6109

Figura 3 - Ranking das Regiões Brasileiras com Oferta de Cursos Superiores a Distância pelos IF

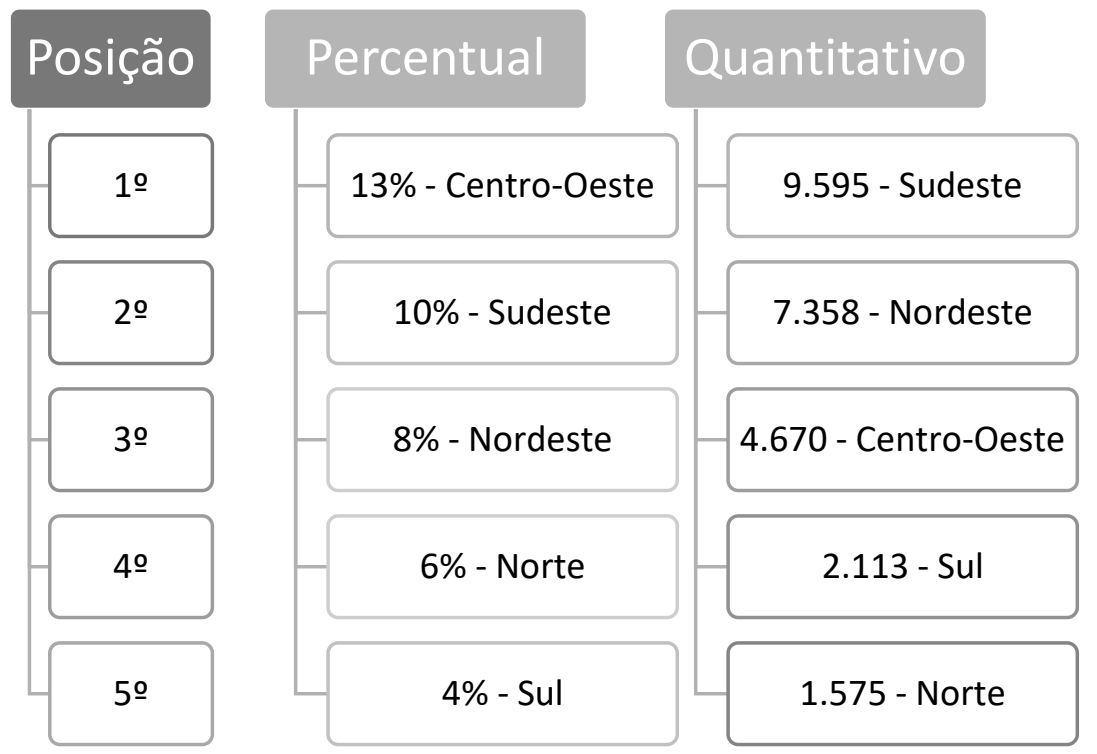

Fonte: Elaborado pelos autores com base na PNP 2020

Figura 4 - Mapa Quantitativo da Oferta de Cursos Superiores a Distância pelos IF CURSOS POR ESTADO E REGIĀO

REGIÃO -CENTRO-OESTE @ NORTE - REGIÃO NORDESTE, BRASIL @ SUDESTE • SUL

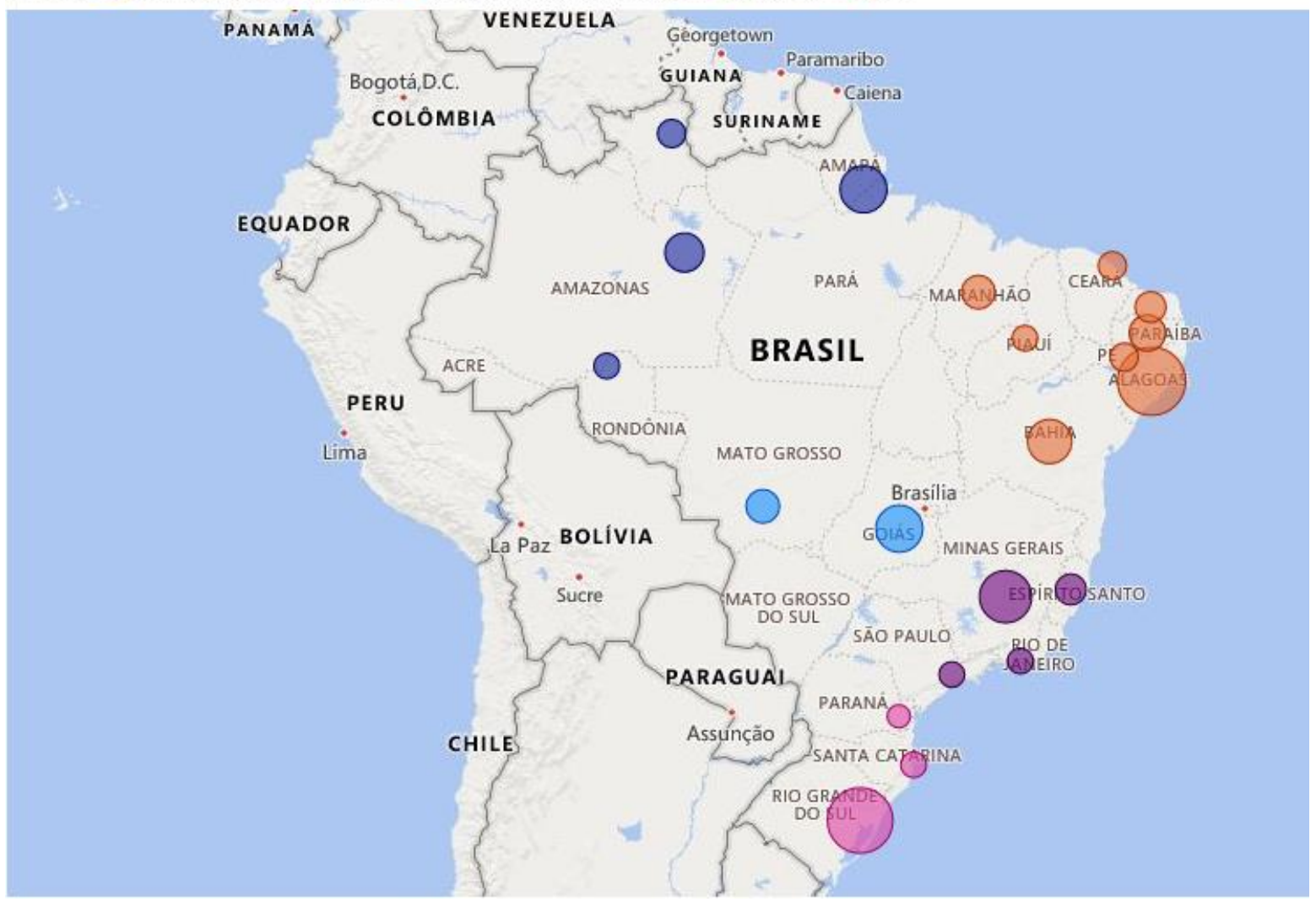

Fonte: Elaborado pelos autores com base na PNP 2020 


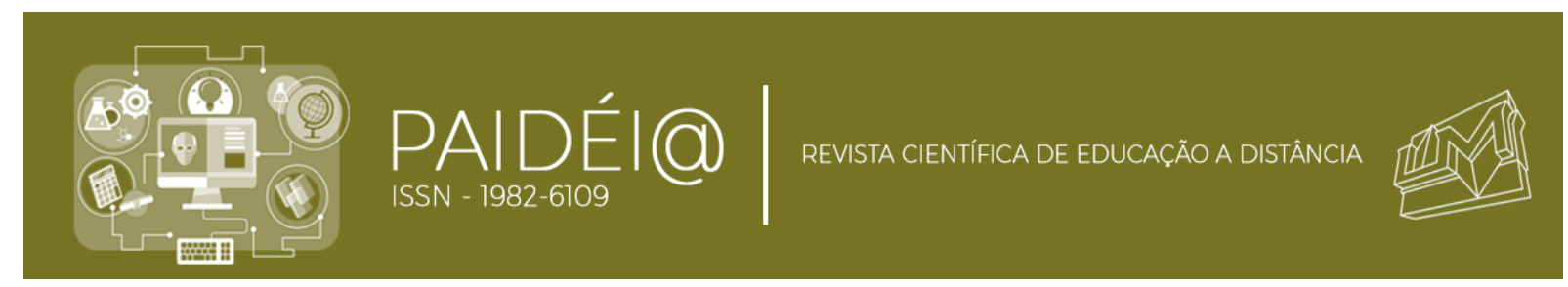

Em continuidade as variáveis dispostas na Tabela 2, seguiremos a discussão a partir dos resultados apurados a partir da análise da oferta dos IF da educação superior na modalidade a distância considerando o tipo de curso superior.

Com base na análise de dados disponíveis na PNP 2020, verifica-se que o Bacharelado é o tipo de curso superior a distância com menor oferta entre os IF, cujas ocorrências são identificadas nas regiões Nordeste (4) e Sudeste (3), apesar da oferta de seiscentos e sessenta e seis na modalidade presencial. Assim, apenas 1\% dos Bacharelados nos IF são através da $\mathrm{EaD}$. Mesmo nas regiões em que há oferta, os indicadores percentuais são bem incipientes, sendo $3 \%$ e $1 \%$, respectivamente entre o Nordeste e Sudeste.

Na região Nordeste, a oferta de Bacharelados através da EaD é do curso em Administração, sendo em 3 unidades de ensino de Alagoas e 1 na Paraíba, totalizando 265 discentes. No Sudeste, além também do curso de Administração em Minas Gerais que registrou uma base de 456 discentes, também há oferta do curso de Engenharia de Produção no Rio de Janeiro, o qual está com 1.684 registradas na PNP 2020.

As Licenciaturas ocupam posição majoritária no tocante a oferta de cursos superiores à distância nos IF, sendo um total de 106 cursos do total de 127 ofertados em âmbito nacional $(83 \%)$, conforme mostra a Tabela 2. Apesar da expressividade identificada, quando apurase pelo indicador em termos percentuais, todas as regiões estão abaixo de $20 \%$, sendo a média nacional em torno de $13 \%$. A região Nordeste detém os melhores indicadores no viés quantitativo (40) de larga diferença às demais regiões (Norte - 22; Sudeste - 16; Sul - 15; Centro-Oeste -13); mas cai para a terceira, juntamente com a região Sul, quanto ao percentual (13\%). Em segundo lugar ficar o Centro-Oeste com $16 \%$ e o Sudeste tem a última posição com $10 \%$. O ranqueamento e o mapa quantitativo da oferta de cursos a distância pelos IF nas regiões brasileiras são mostrados nas Figura 5 e Figura 6, respectivamente.

Alusivo aos cursos de Tecnologia, a oferta se dá em quatro dentre as cinco regiões brasileiros, sendo o Norte aquela que não registrou oferta em 2019, com base nos dados dispostos na PNP 2020. Contudo, mesmo considerando a oferta existente, comparando a oferta entre o presencial e a distância, os percentuais são muito ínfimos, variando entre 3\% (Nordeste e Sul), 2\% (Centro-Oeste) e 1\% (Sudeste). 


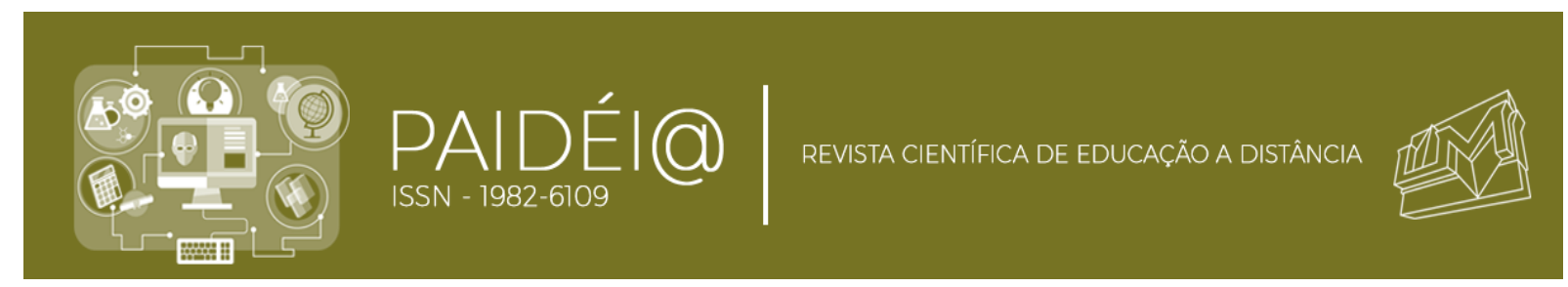

Em uma análise mais detalhada dos dados da PNP 2020 sobre a oferta de cursos de Tecnologia à distância nas regiões brasileiras, foi identificado que o Nordeste dispõe do curso de Hotelaria no Ceará com 373 matriculados e no estado de Alagoas com 6 discentes; e o de Gestão Ambiental em Pernambuco (178 matrículas) e no Rio Grande do Norte (156 matrículas). No Sudeste destaca-se o curso de Gestão de Turismo com 2.257 matrículas no Rio de Janeiro, além também o de Análise e Desenvolvimento de Sistemas no Espírito Santo com 7 matrículas.

Na região Centro-Oeste, ainda sobre a oferta na modalidade a distância de cursos de Tecnologia, conforme a PNP 2020, o estado do Mato Grosso registrou 1.358 matrículas, sendo o curso de Sistemas de Internet com 1.324 matriculados e as demais 34 matrículas no curso de Segurança Pública. Na região Sul os estados do Paraná, Santa Catarina e Rio Grande do Sul ofertam, respectivamente: Segurança Pública (351 discentes); Gestão Pública (280 matrículas) e Sistemas para Internet (123 matrículas).

\section{Figura 5 - Ranking das Regiões Brasileiras por Matrículas em Cursos Superiores a} Distância nos IF

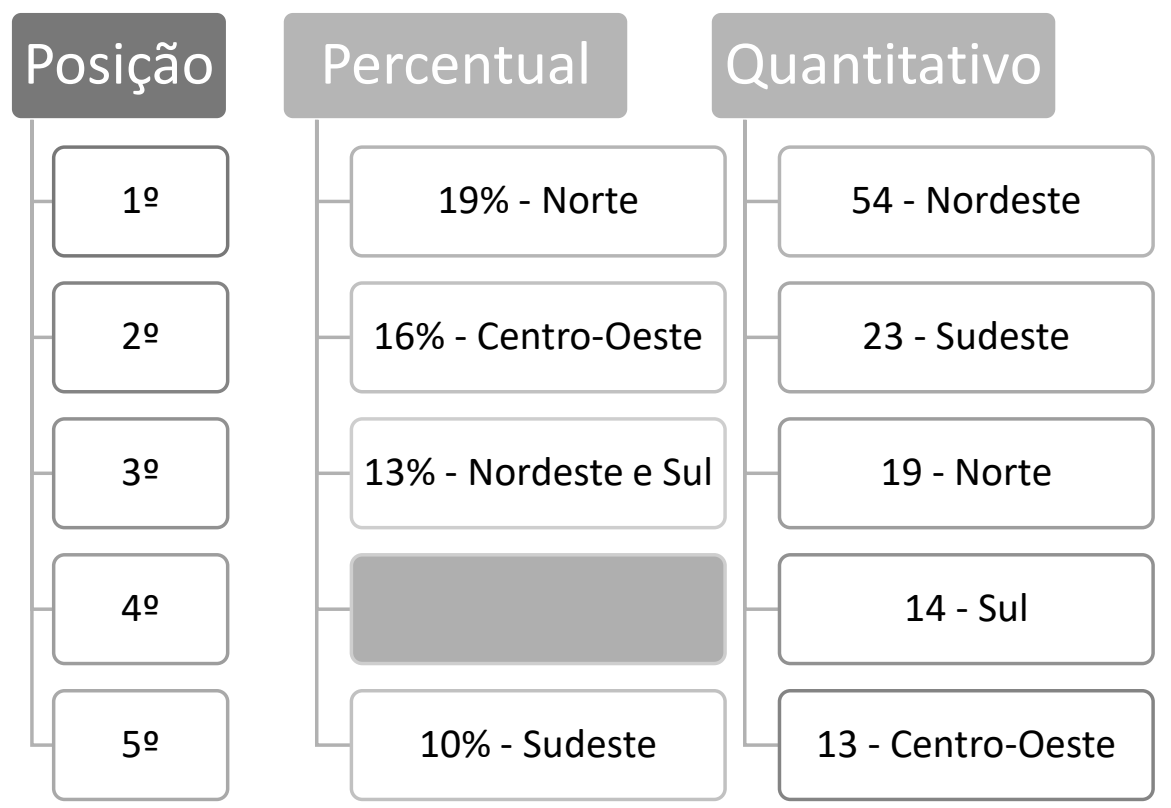

Fonte: Elaborado pelos autores com base na PNP 2020 


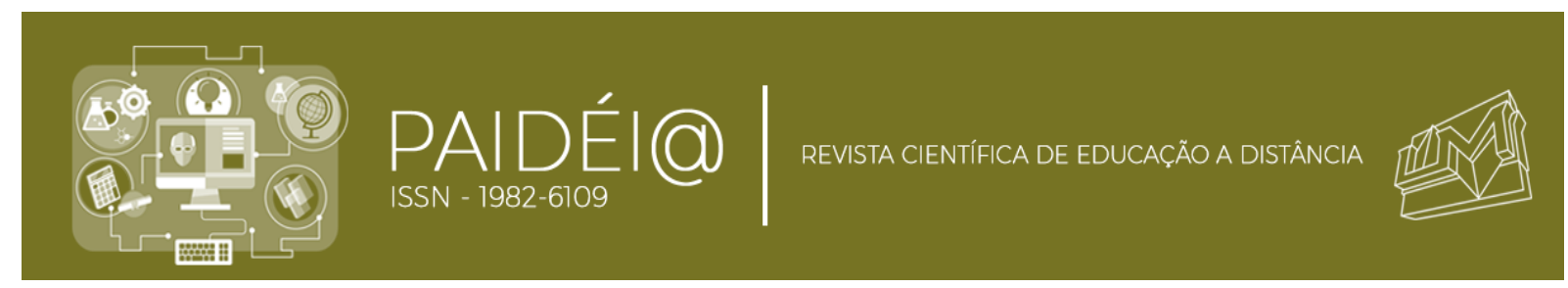

Figura 6 - Mapa Quantitativo de Matrículas em Cursos Superiores a Distância nos IF

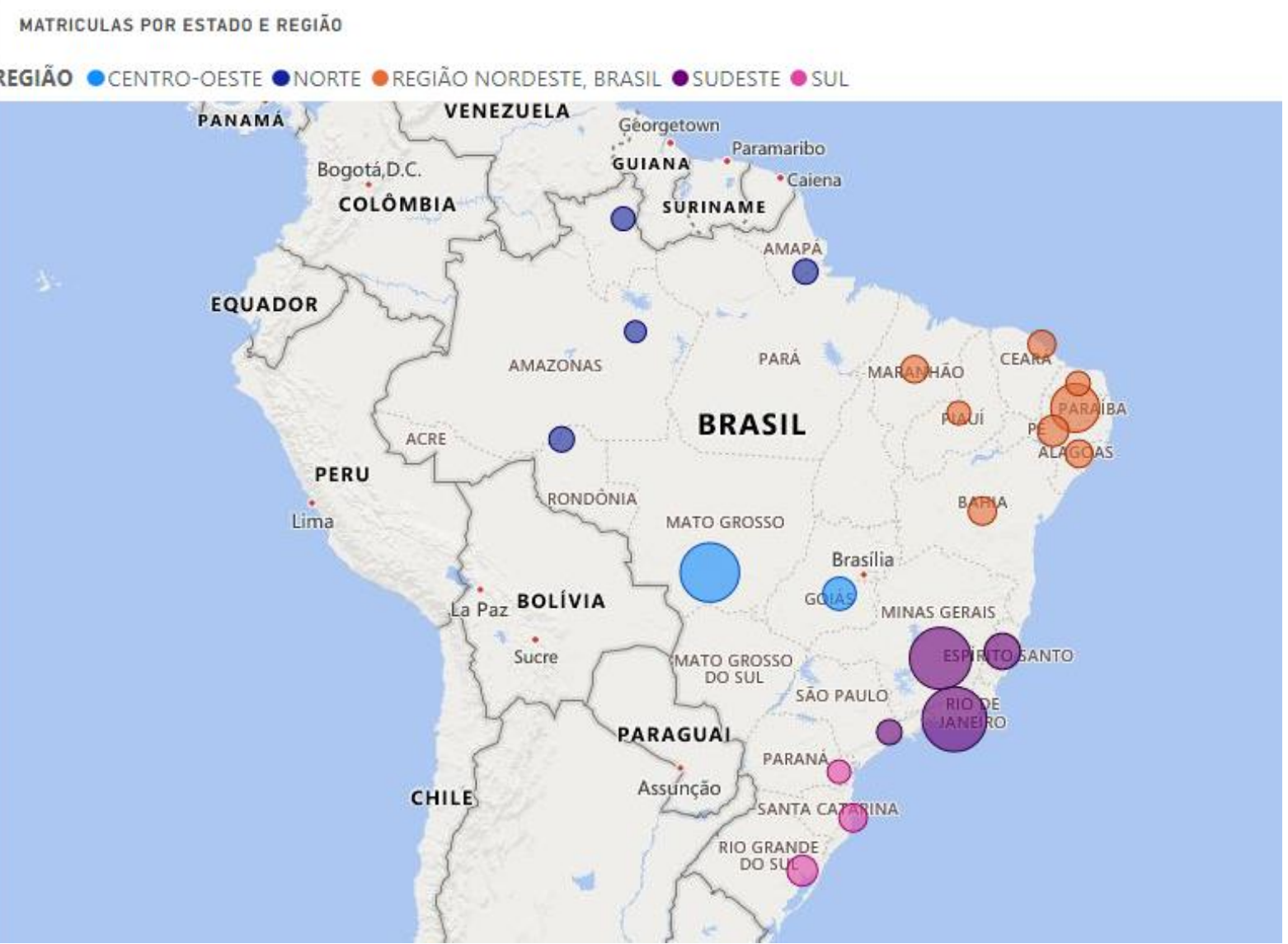

Fonte: Elaborado pelos autores com base na PNP 2020

\section{Conclusões}

Instituídos num período em que a $\mathrm{EaD}$ já era reconhecidamente uma modalidade de ensino que pode ser aplicada à formação em mais diversos níveis de ensino, com legislação atinente ao tema expressa pelo governo federal na LDB, em leis e regulamentos seguintes, além da vasta literatura discutindo a temática, permite-se concluir que apurar um indicador de $6 \%$ no âmbito da oferta nacional de cursos superiores à distância aquém da expectativa. Considerando o período de 10 anos, temos um crescimento de pouco mais de $0,5 \%$ ano.

Este trabalho não tem qualquer objetivo em desmerecer o trabalho que os IF vem realizando ao longo dos seus anos, que vão além da sua institucionalização em 2008; no entanto, 
corroborando com a realidade de atender um quantitativo maior da sociedade brasileira, uma vez que a média de alunos por curso superior EaD é cerca de $60 \%$ superior ao presencial, a referida modalidade pode beneficiar a ampliação da base de alunos sem necessidade, por exemplo, da construção de novas unidades de ensino e a formação de equipe de força de trabalho completa.

Considerando a previsão orçamentária que o valor pago pelo governo federal por aluno matriculado na modalidade a distância é equivalente a $80 \%$ do presencial, deve-se considerar o benefício de ampliação da receita com pequeno incremento das despesas operacionais, o que poderia potencializar a capacidade de investimento, por exemplo, em laboratórios de informáticas e ampliação da largura de banda de internet disponível.

Consoante aos tipos de cursos superiores ofertados através da $\mathrm{EaD}$, concluiu-se que, a partir o quantitativo e percentual de oferta de Licenciaturas num total de 126 cursos (16\% da oferta nacional), os IF têm contribuído relevantemente ao país no quesito de formação docente. No que concerne ao Bacharelado com um quantitativo bem mínimo se comparado aos demais tipos de cursos é compreensível e até mesmo previsto, tanto no presencial como a distância, pela sua natureza institucional. Todavia, o indicador percentual quanto a oferta de cursos de Tecnologia a distância ser em $2 \%$ no âmbito nacional (15 cursos ofertados) aponta a necessidade em averiguar os motivos para a predominância pelo presencial.

Ademais a questões orçamentárias e de indicadores numéricos, em função da exigência de se empreender ações no âmbito do ensino remoto por causa da pandemia do novo coronavírus, que obrigou a paralisação das aulas presenciais, a experiência na oferta de cursos superiores a distância deve ter contribuído com a gestão no planejamento e organização das novas estratégias do ensino mediado por tecnologias, seja elas digitais ou não. Assim, poderá ser alvo de pesquisas posteriores também apurar se essa experiência representou um diferencial relevante na manutenção da oferta do ensino a comunidade acadêmica.

\section{Referências}




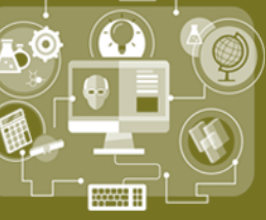

BRASIL. Lei de Diretrizes e Bases da Educação Nacional, n 9394/96, de 20 de dezembro de

1996.

Brasília:

MEC.

Disponível

em:

http://www.planalto.gov.br/ccivil_03/leis/19394.htm. Acesso em: 20 abr. 2020.

BRASIL. Decreto $N^{\circ}$ 9.057, de 25 de maio de 2017. Regulamenta o art. 80 da Lei no 9.394, de 20 de dezembro de 1996, que estabelece as diretrizes e bases da educação nacional. Disponível em: http://www.planalto.gov.br/ccivil_03/_ato20152018/2017/decreto/d9057.htm. Acesso em: Acesso em: 25 abr. 2020.

BRASIL. Lei No 10.861, de 14 de abril de 2004. Institui o Sistema Nacional de Avaliação da Educação Superior - SINAES e dá outras providências. Disponível em: http://www.planalto.gov.br/ccivil_03/_ato2004-2006/2004/lei/110.861.htm. Acesso: 20 abr. 2020.

BRASIL. Lei No 12.772, de 28 de dezembro de 2012. Dispõe sobre a estruturação do Plano de Carreiras e Cargos de Magistério Federal, dentre outros; e dá outras providências. Disponível em: http://www.planalto.gov.br/ccivil_03/_ato20112014/2012/lei/112772.htm. Acesso em: 23 abr. 2020.

BRASIL. Lei No 11.892, de 29 de dezembro de 2008. Institui a Rede Federal de Educação Profissional, Científica e Tecnológica, cria os Institutos Federais de Educação, Ciência e Tecnologia, e dá outras providências. Disponível em: http://www.planalto.gov.br/ccivil_03/_ato2007-2010/2008/lei/111892.htm. Acesso em: 20 abr. 2020.

BRASIL. PNP 2020. Plataforma Nilo Peçanha 2020. Disponível em: http://plataformanilopecanha.mec.gov.br/2020.html. Acesso em: 19 jun. 2020

MUSSIO, Simone Cristina. Reflexões sobre as modalidades de estudo na educação a distância: benefícios e limitações. Revista EDaPECI - Educação a Distância e Práticas Educativas Comunicacionais e Interculturais. v.20 . n. 1, p. 119-129 jan./abr. 2020. DOI:http://dx.doi.org/10.29276/redapeci.2020.20.112187.119-129. Disponível em: https://das.revistas.ufs.br/index.php/edapeci/article/view/12187. Acesso em: 10 mai. 2020.

SEBASTIÃO, Ana Paula Ferreira. A utilização do ambiente virtual de aprendizagem MOODLE em uma instituição de ensino superior pública. Revista Profissão Docente 


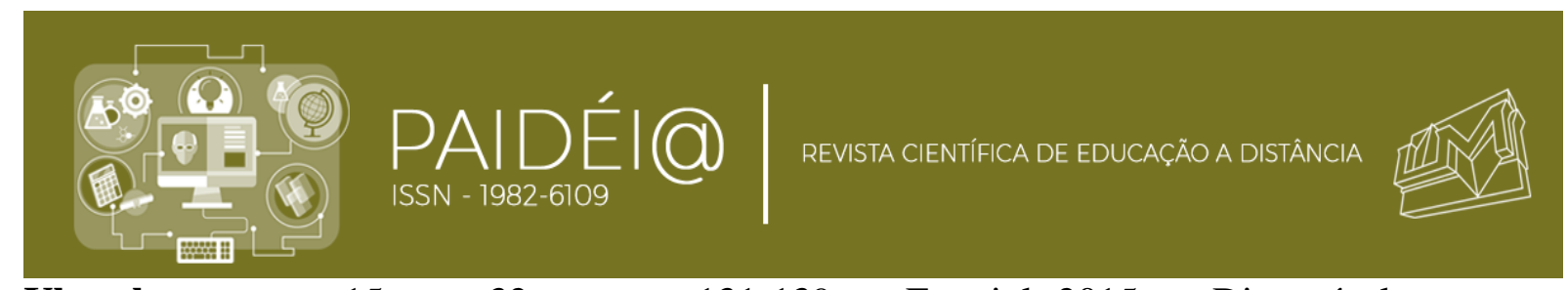

Uberaba, v. 15, n.32, p. 131-139, Fev.-jul.-2015. Disponível em: http://www.revistas.uniube.br/index.php/rpd/article/view/838/1135. Acesso em: 10 mai. 2020.

MORAN, José Manuel. Contribuições para uma pedagogia da educação online. In: SILVA, Marco (org.). Educação online: teorias, práticas, legislação, formação corporativa. São Paulo: Edições Loyola, 2011.

TARCIA, Rita Maria Lino; COSTA, Silvia Maria Coelho. Contexto da educação a distância. In: CARLINI, Alda Luiza; TARCIA, Rita Maria Lino(org.). $20 \%$ a distância e agora? Orientações práticas para o uso de tecnologias de educação a distância no ensino presencial. São Paulo: Pearson Education do Brasil, 2010.

OLIVEIRA, Maxwell Ferreira. METODOLOGIA CIENTÍFICA: um manual para a realização de pesquisas em administração. Universidade Federal de Goiás. 2011. Disponível em: https://files.cercomp.ufg.br/weby/up/567/o/Manual_de_metodologia_cientifica__Prof_Maxwell.pdf. Acesso em: 30 jun. 2020.

FAVERI, Dinorá Baldo; PETTERINI, Francis Carlo; BARBOSA, Marcelo Ponte. Uma avaliação do impacto da política de expansão dos institutos federais nas economias dos municípios brasileiros. Planejamento e Políticas Públicas (PPP). No 50 - jan./jun. 2018. Disponível em: https://www.ipea.gov.br/ppp/index.php/PPP/article/view/742. Acesso em: 20 Abr. 2020. 


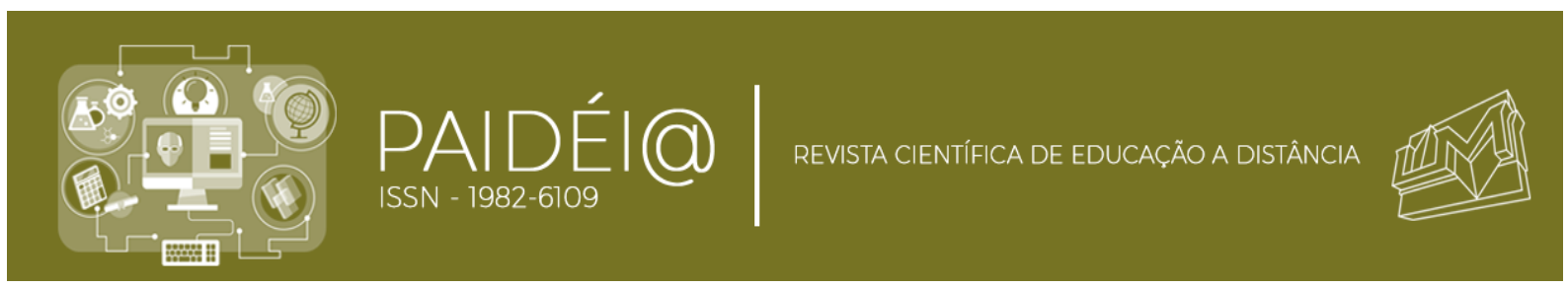

Cleberton Carvalho Soares

Mestre em Sistema e Computação Instituto Federal de Sergipe

Danielle Amaral Menendez

Mestre em Sistema e Computação Instituto Federal de Sergipe

Andrés Ignácio Martinez Menendez

Mestre em Informática Universidade Federal de Sergipe

Artigo recebido em:25/07/2020

Aceito para publicação em: 20/01/2021

Para citar este trabalho:

SOARES, Cleberton Carvalho; MENENDEZ, Danielle Amaral; MENENDEZ, Andrés Ignácio Martinez. INDICADORES DE OFERTA DA EDUCAÇÃ̃o À DISTÂNCIA NA REDE FEDERAL DE EDUCAÇÃO PROFISSIONAL, CIENTÍFICA E TECNOLÓGICA APÓS 10 ANOS DE INSTITUCIONALIZAÇÃO. Revista Paidéi@. Unimes Virtual. Volume 13-Número 23. Janeiro 2021. Disponível em:

https://periodicos.unimesvirtual.com.br/index.php/paideia/index 


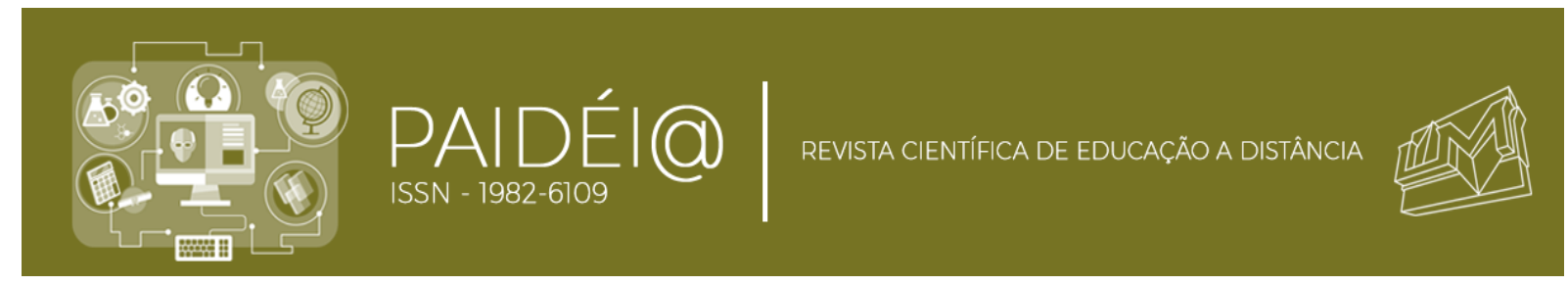

